DOI: https://doi.org/10.21728/logeion.2018v5n0.p8-26

\title{
JÜRGEN HABERMAS: UMA TEORIA DA COMUNICAÇÃO HUMANA
}

\author{
Flávio Beno Siebeneichler
}

\section{RESUMO}

A comunicação pretende chamar a atenção para pontos fundamentais da teoria do agir comunicativo, de Jürgen Habermas, que está centrada na comunicação e na vulnerabilidade humana que é fruto da própria comunicação. Será utilizada uma estratégia de exposição dividida em três etapas: A primeira etapa terá duas séries de observações gerais sobre a vida e a obra de Habermas. Na segunda etapa o texto é concentrado em dois pontos de extrema relevância na teoria do agir comunicativo: aa relação dialética com a teoria de Emanuel Kant; e, o critério de acoplabilidade interdisciplinar entre princípios teóricos distintos o que lhe permite soletrar um projeto de teoria da sociedade entendida como crítica da razão ontológica. A terceira etapa abordará problemas derivados do conceito complexo e bipolar da sociedade que depende de possibilidades de acoplagem entre mundo da vida e sistema.

Palavras-chave: Teoria da Ação Comunicativa, Habermas, Teoria Habermasiana.

\begin{abstract}
The communication aims to draw attention to the fundamental points of Jürgen Habermas' theory of communicative action, which is centered on communication and human vulnerability that is the fruit of communication itself. An exposition strategy divided into three stages will be used: The first stage will have two series of general observations on the life and work of Habermas. In the second stage the text is concentrated in two points of extreme relevance in the theory of communicative action: the dialectical relation with the theory of Emanuel Kant; and the criterion of interdisciplinary coupling between distinct theoretical principles that allows him to spell a project of society theory understood as a critique of ontological reason. The third stage will address problems derived from the complex and bipolar concept of society that depends on possibilities of coupling between the world of life and the system.
\end{abstract}

Keywords: Theory of Communicative Action, Habermas, Habermasian Theory. 


\section{PRÓLOGO}

Jürgen Habermas é, sem dúvida alguma, o autor mais produtivo, controverso, e influente da atualidade. $\mathrm{O}$ fato de ter sido agraciado com inúmeros títulos e prêmios acadêmicos conferidos pelas mais prestigiadas universidades ao redor do mundo, inclusive o Prêmio Kyoto em 2004, revela que ele também é uma personalidade reconhecida na área da ciência e da cultura, mesmo que o caráter revolucionário de sua obra ainda não tenha sido bem compreendido.

Seus trabalhos são amplamente debatidos não somente na área da filosofia, mas também na das ciências sociais, especialmente na esfera da teoria política e das relações internacionais, onde já é considerado um clássico. Sua teoria da democracia radical serve como uma espécie de cabeça-de-ponte teórica para pesquisas empíricas dos mais diferentes tipos.

Nesta comunicação pretendo chamar a atenção para pontos fundamentais da teoria do agir comunicativo, de Jürgen Habermas, que está centrada na comunicação e na vulnerabilidade humana que é fruto da própria comunicação.

E para atingir meu assaz difícil objetivo, dada a amplitude e complexidade desta teoria revolucionária, vou adotar a estratégia de uma exposição dividida em três etapas distribuídas da seguinte maneira:

$\mathrm{Na}$ primeira apresentarei duas séries de observações gerais sobre a vida e a obra de Habermas.

$\mathrm{Na}$ segunda etapa me concentro em dois pontos que considero de extrema relevância na teoria do agir comunicativo, a saber:

a) Sua relação dialética com a teoria de Emanuel Kant;

b) O critério de acoplabilidade interdisciplinar entre princípios teóricos distintos o que lhe permite soletrar um projeto de teoria da sociedade entendida como crítica da razão ontológica.

$\mathrm{Na}$ terceira etapa abordarei problemas derivados do conceito complexo e bipolar de sociedade que depende de possibilidades de acoplagem entre mundo da vida e sistema.

\section{OBSERVAÇÕES GERAIS SOBRE A VIDA E A OBRA DE JÜRGEN HABERMAS}

\subsection{Sobre a vida de Jürgen Habermas}


Nascido em Düsseldorf, Alemanha, em 18 de junho de 1929, Habermas passou por experiências extremamente dolorosas que marcaram decisivamente o início de sua vida e, inclusive, suas decisões teóricas posteriores. Em primeiro lugar, a necessidade de reconstituição cirúrgica do palato foi causa de isolamento e sérios obstáculos à comunicação desde a idade pré-escolar. Além disso, o choque recebido na juventude ao tomar ciência do extermínio em massa de judeus durante a II Guerra nos campos de concentração nazistas o confrontou com a dolorosa experiência de que o regime em que vivera era criminoso.

Ao entrar para a universidade dedicou-se ao estudo da filosofia, da psicologia, da literatura alemã e da economia em Göttingen, Zurique e Bonn onde apresentou, em 1954, uma tese sobre o absoluto e a história na filosofia de Schelling. Passou a trabalhar, logo a seguir, como jornalista autônomo.

A título de ilustração, acho interessante destacar, entre os comentários e recensões publicados nesta época, principalmente no semanário Frankfurter Allgemeine Zeitung, os seguintes:

- À luz de Heidegger (1952).

- As chances do drama radiofônico residem nas suas falhas.

- O palco acústico. Notas sobre Adamov, Dürrenmatt e Huber.

- A ironia das cabeças de madeira e de gesso. Por ocasião do Ciclo Internacional do teatro de marionetes.

- O Moloch e as artes.

- Sobre o potencial de cura da arte.

- Três máscaras demais.

- Filosofia é risco.

- O poder impessoal da burocracia moderna.

- Os funcionários necessitam de fantasia.

- A massa somos nós.

- Dirigir carro. O homem ao volante.

- Férias químicas do eu.

- O espírito vai a pé.

- Tomás de Aquino contra Hegel.

- Ilusões no mercado de casamentos.

- Reconciliação entre psicanálise e religião (1957). 
Em 1956 aceitou uma bolsa de assistente de pesquisa no Instituto para Pesquisa Social da Universidade de Frankfurt, onde trabalhou ao lado de Theodor W. Adorno. Em 1961 defendeu, na universidade de Marburg, sua tese de habilitação sobre a Mudança estrutural da esfera pública. Neste mesmo ano foi convidado por Hans-Georg Gadamer para assumir a função de professor extraordinário de filosofia social na Universidade de Heidelberg, onde permaneceu até 1964, ano em que assumiu a cátedra de filosofia e sociologia na Universidade de Frankfurt. Em 1971 proferiu as Christian Gauss-Lectures na Universidade de Princeton. Neste mesmo ano, após acalorados debates com o movimento dos estudantes, renunciou à cátedra da Universidade de Frankfurt e aceitou o convite de Carl Friedrich von Weizsäcker para ser co-diretor do recém-criado Instituto Max Planck voltado para a pesquisa sobre as condições de vida no mundo da ciência e da técnica. Em 1980 tornou-se o diretor desse Instituto, cargo que ocupou até 1983 quando reassumiu a cátedra de filosofia e sociologia em Frankfurt. Aposentou-se como professor emérito em 1994.

É interessante notar que, mesmo após seu retorno à academia, Habermas continuou vinculado ao Instituto Max Planck na qualidade de membro de pesquisa externo. Em 1984 ministrou as Messenger-Lectures na Universidade de Cornell e, em 1986, as Tanner-Lectures na Universidade de Harvard. Em 1988 esteve no Brasil proferindo conferências na UFRS, na USP e na UFRJ.

\subsection{Observações gerais sobre a obra de Jürgen Habermas}

A compreensão correta do pensamento desse autor prolífico e revolucionário constitui um grande desafio porquanto ele se dedica, de um lado, à formulação de um vínculo entre a teoria e a práxis (1962), o que lhe permite criar nexos entre o conhecimento e os interesses que o provocam (1968); entre questões de sentido e de validade (1972); entre as teorias analíticas e o perspectivismo hermenêutico (1999); entre a ciência filosófica e análises sociológicas; entre o direito, a moral e a democracia (1992); entre a religião e o naturalismo (2005). Tal vínculo é importante para a construção de uma teoria voltada explicitamente para o esclarecimento e a emancipação humana, pois, lhe permitiu conceber, desde o início, uma filosofia que, a exemplo da de K. Marx, S. Freud, H. Marcuse, T. W. Adorno, E. Bloch, H. Arendt e W. Benjamin, não se encerra nos muros de uma academia nem se dedica ao refinamento de sistemas teóricos bem ordenados, brilhantes, porém, estéreis do ponto de vista prático da configuração racional e solidária de uma sociedade humana. Nenhum desses 
autores, que são tomados como modelo de seu pensamento, pode ser tido na conta de pensador acadêmico em sentido estrito ou de um pensador da ordem estabelecida.

De outro lado, a teoria habermasiana, inspirada em uma linha pragmática, hermenêutica e analítica, rompe audaciosamente com o platonismo da filosofia tradicional que pressupunha a existência de um ideal sublime ou critério de verdade superior a ser tomado como ponto de referência obrigatório de nossas investigações em geral.

Ele trabalha, além disso, com a hipótese de que a sua nova filosofia pós-platônica e pós-kantiana tem por tarefa substituir o paradigma subjetivista e monológico da filosofia moderna por outro paradigma: o intersubjetivista. Haja vista que o espírito subjetivo adquire, por assim dizer, conteúdo e estrutura a partir de uma ancoragem no espírito objetivo formado por relações intersubjetivas que se estabelecem por uma comunicação entre sujeitos que, por natureza, se socializam em determinados contextos e dependem da socialização comunicativa para se tornarem eles mesmos, seres autônomos e individuais. Na linha desta interpretação, a consciência particular de um sujeito jamais pode ser considerada, a rigor, privada, tendo em vista que ela, de fato e até mesmo nos movimentos mais recônditos, alimenta-se de fluxos de uma rede cultural de informações, valores e pensamentos públicos expressos simbolicamente por linguagem e compartilhados intersubjetivamente. Nessa ontologia habermasiana, o sujeito humano é considerado um animal dotado da capacidade de falar e agir. E para desenvolver tal competência comunicativa que o transforma em pessoa ele necessita de um espaço público tecido de relações sociais em uma prática comunicativa cotidiana orientada por entendimento intersubjetivo.

Além disso, a nova filosofia pós-platônica lança fora a clássica metáfora kantiana que compara a filosofia a um tribunal das ciências. No seu lugar entram as metáforas de um intérprete do mundo da vida sociocultural e de um guardião da racionalidade que tenta elaborar, em cooperação com as ciências sociais e humanas, uma teoria da racionalidade comunicativa. E esta tarefa tem de ser realizada sem acalentar pretensões fundamentalistas ou absolutistas.

Finalmente, convém destacar o caráter fragmentário que transparece na obra habermasiana. Ele aprendeu, com Wittgenstein, que uma obra filosófica pós-metafísica não pode alimentar pretensões de uma doutrina inconsútil apoiada em princípios a priori ou estruturas últimas. Por isso, ela assume funções mais modestas de mediação e clarificação lógica, de explanação de pensamentos e compreensões encontradas já prontas que são submetidas a uma análise crítica em um discurso argumentativo. 
Tais características constituem, sem dúvida alguma, a principal causa das dificuldades sentidas por muitos leitores de Habermas: Eles procuram uma doutrina bem estruturada e acabada, vertida em tratados sistemáticos. E somente encontram estudos, ensaios, críticas, apontamentos, reconstruções racionais, retomadas de ideias anteriores, conjeturas, comentários, réplicas, aclarações, explanações, explicações, excursos, justificações de pretensões de validade e outras formas de argumentação. Entretanto, ele parece não se incomodar com esse fato uma vez que ele aprendeu - com T. W. Adorno - a colocar o todo de sua teoria em cada um desses blocos argumentativos. E o leitor atento logo se dá conta disso.

A teoria do agir comunicativo, formulada em termos de uma teoria crítica da sociedade, de cunho filosófico e sociológico, constitui o ponto de confluência de todo o labor racional habermasiano. Convém sublinhar que sua formulação e fundamentação não se resumem aos dois grossos volumes, contendo 1175 páginas, publicados em 1981: elas transparecem nos demais textos e blocos de argumentação. Mesmo assim e apesar de seu feitio fragmentário, essa teoria vem acompanhada de uma pretensão radical e inovadora: elaborar uma crítica da razão ontológica ocidental nos moldes de uma teoria comunicativa da integração social apoiada diretamente sobre uma pragmática formal da linguagem inspirada em Wilhelm von Humboldt. Sua unidade elementar é a ação de fala realizada na linguagem comum cotidiana: "ego procura entender-se com outro ego sobre algo no mundo". Por isso, ela é elaborada na perspectiva performativa de uma segunda pessoa gramatical, o que implica um dualismo de perspectivas metódicas: a de um observador e a de um participante de uma argumentação. De outro lado, ela implica a perspectiva hermenêutico-analítica de um filósofo e o método descritivo de um sociólogo. Como resultado disso tudo, a teoria do agir comunicativo se constrói basicamente sobre três conceitos-chaves: o agir comunicativo; a razão comunicativa que tem sua sede em pretensões de validade que acompanham inevitavelmente o agir comunicativo; e o mundo da vida que se articula no medium da linguagem abrindo para os participantes um horizonte de interpretações do mundo.

\section{A TEORIA DO AGIR COMUNICATIVO}

\subsection{Sua relação dialética com a teoria kantiana}

É interessante observar, inicialmente, que o ano de 1981, data da publicação do opus magnum de Habermas, também marca os duzentos anos da publicação da primeira edição da Crítica da razão pura, de Kant. 
Gostaria de aproveitar essa curiosa coincidência, a fim de destacar o fato de que as duas obras, apesar das evidentes diferenças de pensamento e de paradigma, revelam similaridades que é preciso levar na devida conta quando se pretende chegar a uma compreensão mais adequada da obra habermasiana. Esta se desenvolve numa peculiar tensão dialética com o pensamento kantiano, a ponto de podermos afirmar que Habermas pensa com Kant e, ao mesmo tempo, contra ele. ${ }^{1}$

\subsubsection{Semelhanças}

Sabemos que Kant pretendia conquistar para a filosofia um lugar seguro no domínio das ciências. E ele imaginava que o único método em condições de realizar essa tarefa teria de ser configurado em termos de uma crítica radical da razão capaz de purificar a filosofia das variadas formas de pseudo-saber e das superstições de que era vítima. Na introdução à segunda edição da "Crítica da razão pura", a argumentação kantiana é aparentemente simples:

Até hoje se supunha que nosso conhecimento tem de orientar-se pelos objetos. Neste caso não teríamos chances de explicar o conhecimento. No entanto, se fizermos de conta que os objetos têm de orientar-se por nosso conhecimento é possível explicar melhor a possibilidade do conhecimento (KANT, 1974, v. XVI, XVII) ${ }^{2}$

E Kant insiste nesse ponto ao afirmar um pouco mais adiante:

Teremos mais êxito se imitarmos Copérnico que, ao constatar que a explicação dos movimentos celestes não funcionava enquanto ele pressupunha que o inteiro exército de astros e estrelas se movimentava ao redor do expectador, tentou outra solução, mais eficaz: deixou os astros em paz e fez o expectador girar em torno deles (KANT, 1974, v. XVI, XVII).

Entretanto, ao constatar que tal modo de pensar permitira a Copérnico uma explicação mais consistente dos corpos celestes, Kant sugeriu que se fizesse uma inversão semelhante na filosofia, ou seja: ao invés de imaginar que o pensamento se orienta pelos objetos, devemos nos acostumar a pensar que as coisas se portam segundo nossas formas de representá-las. Por isso, a busca de um conhecimento seguro não deve mais estar centrada nas coisas ou nos

\footnotetext{
${ }^{1}$ Formulo esta frase tendo em mente o ultimo período de um comentário redigido por Habermas em 1953 sobre a publicação de aulas de M. Heidegger sobre metafísica, ministradas em 1935. O teor do período final de Habermas é o seguinte: "Parece chegada a hora em que devemos pensar com Heidegger contra Heidegger". Cf. HABERMAS, 1984, p. 72.

${ }^{2}$ A tradução dos textos em alemão para o português, nesta passagem e em outras deste trabalho, é de minha autoria.
} 
objetos, mas na experiência e na representação do sujeito que tem acesso a elas (KANT, 1974). Porquanto a razão somente consegue compreender o que ela mesma produz segundo traçados que ela gera. Ela busca leis constantes lançando mão de princípios inerentes a seus próprios juízos. Por isso ela precisa "pressionar" a natureza a responder a suas perguntas. Jamais pode deixar-se aprisionar por ela:

A razão dirige-se á natureza tendo em uma das mãos princípios segundo os quais fenômenos coincidentes podem valer como leis e na outra o experimento (destinado a testar essas leis). Não obstante isso, ela não vai à natureza na qualidade de um aluno a ser instruído, que escuta atentamente tudo o que um professor decide dizer. E sim, na qualidade de um juiz que obriga as testemunhas a responderem às perguntas que ele mesmo formula (KANT, 1974, v. XIII, XIV).

De sua parte, Habermas também pretende encontrar um caminho seguro para a filosofia em uma nova era pós-metafísica, que pode ser caracterizada como era da ciência, da técnica, da pesquisa, da inteligência artificial, etc. Isso o obriga a uma nova compreensão de filosofia que o coloca em confronto com o modo moderno de conceber a filosofia. E ele não é nada modesto em sua pretensão, visto que concebe sua obra como uma crítica radical da razão ontológica ocidental, inclusive a kantiana. Segundo ele, o conceito de ontologia utilizado pela filosofia kantiana e pelas ciências em geral está apoiado em uma única relação do sujeito com o mundo, isto é, a relação cognitiva. Aos olhos de Habermas, a filosofia ainda não conseguiu criar um conceito mais amplo capaz de incluir, não somente a relação cognitiva do sujeito com o mundo objetivo, mas também a sua relação com um mundo social e com o mundo subjetivo (HABERMAS, 1981, p. 75).

Por isso, a teoria do agir comunicativo pretende, não somente preencher tal lacuna da filosofia ocidental, mas ainda e principalmente, colocar nos trilhos seguros da ciência uma teoria social pós-metafísica, que também pode ser caracterizada como teoria dos fundamentos comunicativos da integração social. Ela tem na mira a criação de nexos entre o conhecimento e os interesses que o provocam, entre questões de sentido e de validade, entre a filosofia e as ciências, entre a teoria e a práxis. Trata-se, pois, de uma filosofia interdisciplinar voltada para o esclarecimento e a emancipação humana, a qual, a exemplo da teoria de K. Marx, de W. v. Humboldt e outros, se preocupa com as patologias da modernização capitalista e com os fundamentos normativos de uma sociedade em geral. E nesse ponto têm início diferenças de Habermas com Kant.

\subsubsection{Diferenças}


A teoria habermasiana submete, inicialmente, o próprio método kantiano a uma espécie de guinada copernicana ao sugerir que, ao invés de pensarmos o conhecimento orientado por uma razão centrada no sujeito singular, devemos pensar, inversamente, que o sujeito se orienta por uma razão inserida em uma comunicação linguística com outros sujeitos. Isso leva a afirmar que o sujeito, nas suas tentativas de conhecimento de algo, gira de certa forma em torno de outros sujeitos, já que o conhecimento racional resulta de um intercâmbio linguístico entre eles.

É possível condensar as semelhanças e dessemelhanças entre os projetos teóricos dos dois pensadores em foco lançando mão de alguns pontos mais marcantes especialmente os seguintes:

- Para Kant, o autoconhecimento transcendental intuitivo da razão humana desenvolve-se no interior de um sujeito solitário que reflete sobre si mesmo. Isso permite afirmar que no início de qualquer processo racional temos uma relação, que Habermas caracteriza como monológica, entre um sujeito transcendental e o seu objeto. Ao passo que a visão teórica habermasiana, que se posiciona pragmaticamente perante esse forte transcendentalismo monológico, coloca, no início do conhecimento, sujeitos providos das faculdades de fala e ação, os quais, ao pretenderem chegar a um entendimento sobre o conhecimento de algo no mundo, se encontram preliminarmente em uma relação intersubjetiva. Por esta razão, Habermas é obrigado a concentrar-se nas estruturas intersubjetivas de um possível entendimento entre sujeitos. E o paradigma da razão assume neste caso a forma de uma racionalidade "comunicativa" inserida em uma relação interativa entre um Ego e um Alter.

- A dedução de conceitos puros da razão a partir de uma consciência transcendental, elaborada por Kant, visara um conhecimento seguro e apoiado em fundamentos últimos ou primeiros. Habermas pretende evitar tal fundamentalismo da filosofia transcendental e deixa isso bem claro: no último pensamento expresso no derradeiro parágrafo da Teoria do agir comunicativo ele formula um repúdio inequívoco de pretensões fundamentalistas. Isso porque, no seu entender, a reconstrução pragmático-formal do saber utilizado por sujeitos falantes e agentes, que se encontram imersos numa dupla contingência, revela um caráter eminentemente falível, hipotético e, portanto, criticável, não último. 
- Convem destacar, outrossim, que, para Kant, a matemática e as ciências naturais constituíam o ideal da racionalidade científica. Ao passo que Habermas, em que pese a sua pretensão de fundamentar a teoria da sociedade sobre as bases da racionalidade científica, rejeita in limine uma compreensão cientificista, positivista, empirista ou funcionalista da ciência. O segundo volume da "Teoria do agir comunicativo" é dedicado, todo ele, a uma crítica da razão funcionalista, a qual já está anunciada no próprio subtítulo. Por conseguinte, ele não pode mais, por razões de coerência, tomar como protótipo metódico, nem a física, nem a matemática. Neste caso, convém perguntar: faz sentido continuar a pensar na possibilidade de se introduzir a nova concepção de filosofia pós-metafísica ou de teoria da sociedade no caminho seguro dos padrões rigorosos da ciência a partir do momento em que não se pode mais tomar as ciências exatas como protótipo?

\section{(Passagem para a temática habermasiana)}

A abordagem dessa questão leva Habermas a tomar duas decisões importantes que vão repercutir em todo o trabalho teórico posterior.

Primeira decisão: Ele adota um dualismo metódico que permite novas configurações entre a filosofia e as ciências, já que o obriga a levar em conta duas perspectivas metódicas distintas e complementares, a saber: a perspectiva de um observador objetivo especializado em linguagens científicas, a qual permite adquirir um saber de fatos "duros" e cujo critério consiste na objetividade da observação; e a perspectiva participante de um intérprete hermenêutico que o próprio observador é obrigado a adotar, já que ela permite compreender, por meio da linguagem, conjuntos simbólicos, cujo critério é a intersubjetividade do entendimento (HABERMAS, 2005, p. 12 e 213). As duas perspectivas são complementares, porque nem tudo aquilo a que temos acesso em uma delas pode ser atingido inteiramente na outra. Por isso mesmo, tal dualismo é vantajoso já que permite acoplar explicações filosóficas sobre condições de racionalidade a análises empíricas de estruturas de racionalidade incorporadas na história.

Segunda decisão: Ele toma como eixo central do seu trabalho a racionalidade das ações de sujeitos e a racionalização da sociedade em geral porquanto ambas podem ser abordadas, tanto por uma filosofia pós-metafísica como por uma sociologia não empirista desde que esta não seja vista apenas como pura descrição de fatos. Na compreensão de Habermas, já que a problemática da racionalidade é incontestável nesses dois campos, ela permite colocar a questão central da teoria do agir comunicativo nos seguintes termos: será 
que processos de modernização da sociedade podem ser analisados sob pontos de vista de uma racionalização de contextos da vida sociocultural e, nesse caso, também sob o ângulo crítico de uma racionalização "colonizadora" do mundo da vida moderno por meios sistêmicos?

Não há espaço, aqui, para o aprofundamento desse ponto. Mesmo assim, é importante lembrar que o conceito de racionalidade adotado por Habermas é suficientemente amplo e geral permitindo procedimentos metódicos orientados por uma possível solução de problemas e questões. Isso possibilita, de um lado, sondar de maneira flexível construções filosóficas mais gerais construídas com fins explanatórios e, de outro lado, testá-las em pesquisas coletivas e cooperativas empreendidas pelas ciências sociais.

E nesse ponto podemos detectar uma diferença, talvez a mais significativa, entre a razão pura, kantiana, e a razão comunicativa, habermasiana. Sabemos, com efeito, que a razão pura dirige-se à natureza na qualidade de um juiz que traz numa das mãos leis ou princípios a priori e na outra um experimento que testa essas leis e força a natureza a responder às perguntas que ele mesmo formula.

Ao passo que a razão comunicativa, que não é pura, assume uma atitude diametralmente oposta, isto é, a atitude de um aluno interessado em aprender - mediante busca de entendimento com outros - com as resistências e relutâncias oferecidas pela natureza e com os atritos, discordâncias e contradições que surgem na sociedade. Por isso ela tem de abandonar a postura de um juiz soberano e autossuficiente que tudo julga em nome da razão.

Tal mudança de compreensão da filosofia modifica igualmente sua relação com as ciências. Apoiada no critério da coerência e na consciência de que é impossível chegar á completude e a uma verdade absoluta, imutável, ela pensa ser possível assumir, mesmo assim, uma relação de cooperação, de busca interdisciplinar da verdade. Nessa relação, o seu trabalho específico continua sendo o da guarda da unidade da razão, porém, não mais em nome de uma totalidade metafísica (ou de uma trincheira do absoluto) e sim, em nome de pretensões de validade resgatáveis em discussões racionais e em nome de uma "totalidade frágil e quebradiça do mundo da vida humano que se configura em comunicação".

Ora, essa nova situação pós-metafísica e interdisciplinar, na qual se encontram a filosofia e as ciências sociais, faz com que venham à tona questões provocadas principalmente pela necessidade de mediação e cooperação entre teorias opostas; entre disciplinas diferentes; entre questões de ciência e tecnologias da informação; entre teoria e práxis; entre ciência e mundo da vida, as quais adquirem importância cada vez maior no mundo de hoje. 
Não pretendo aprofundar esses temas, e sim, chamar a atenção para o fato de que tal trabalho de mediação cooperada implica a possibilidade de estabelecer ligações ou contatos, ou seja, em termos habermasianos, possibilidades de acoplagem. E tal possibilidade constitui, inclusive, um critério fundamental na Teoria do agir comunicativo.

\subsection{Sobre o critério de acoplabilidade}

A teoria da atividade comunicativa foi elaborada com a clara consciência de que, para fazer jus a esse novo estado de coisas, a estrutura de uma teoria da sociedade em geral não pode configurar-se apenas à luz de alguns princípios ou estruturas lógicas a priori. Sua estrutura é aberta, isto é, confeccionada de maneira a permitir ulteriores ligações ou acoplagens com outros princípios e teorias e, inclusive, com outras áreas de especialização ${ }^{3}$. Nas próprias palavras de Habermas:

Eu gostaria de acentuar o caráter inteiramente aberto e as possibilidades de acoplagem inerentes a um princípio de teoria da sociedade cuja fecundidade precisa ser comprovada em pesquisas filosóficas e sociais ramificadas. (HABERMAS, 1981, p. 562)

Em uma obra posterior à Teoria do agir comunicativo intitulada Verdade e justificação (1999) Habermas esclarece, no entanto, que o tipo de acoplagem que ele tem na mente é dialético porquanto constitui uma ligação (Anschluss) entre dois princípios teróricos, não uma simples anexação sincrética (Angleichung) (HABERMAS, 1999, p. 15).

O princípio da acoplabilidade orienta, de um lado, o método de análise de teorias seguido por Habermas, o qual consiste em um exame crítico detido e acurado das pretensões de validade de uma teoria em particular e também das suas possibilidades de acoplagem com outras teorias. De outro lado, esse método marca, por assim dizer, o próprio ritmo da sua linguagem teórica que se desdobra em dois passos principais:

- Em um primeiro momento, ele analisa e desenvolve determinado princípio teórico até o ponto em que ele deixa entrever suas aporias e sua incapacidade de gerar novas acoplagens com outros princípios.

- A seguir, esse ponto insatisfatório é tomado como base a partir da qual ele mesmo tenta a construção de um novo princípio teórico que é submetido, a

\footnotetext{
${ }^{3}$ A visão teórica de Lorenz B. Puntel exclui, no meu entender, tal possibilidade. Cf. PUNTEL, 2008, p. 205-326.

${ }^{4}$ Jan Philip Reemtsma, em uma Laudatio dedicada a J. Habermas por ocasião da entrega do Prêmio da Paz conferido em 2001 pelas editoras e livrarias alemãs, também sublinha o papel importante do princípio da acoplabilidade na obra do agraciado.
} 
seguir, a uma espécie de teste pragmático de acoplagem, isto é, ele passa a analisá-lo sob o ângulo de sua capacidade de fornecer respostas novas a novos desafios.

\section{O CRITÉRIO DA ACOPLABILIDADE NO ÂMBITO DA TEMÁTICA: MUNDO DA VIDA SOCIAL E SISTEMA}

\subsection{Tentativa Habermasiana de acoplagem entre teorias da ação, centradas no mundo da vida, e teorias de sistemas autorregulados}

É interessante notar que as maiores críticas dirigidas á Teoria do agir comunicativo não tem como alvo principal a pragmática formal que sustenta a teoria enquanto tal nem o conceito de agir orientado por entendimento ou agir comunicativo. Elas têm na mira, principalmente, as tentativas habermasianas de acoplagem entre teorias da ação, centradas no conceito de mundo da vida, e teorias de sistemas autorregulados. Tais tentativas seriam ecléticas ou, quando muito, um amontoado de princípios heterogêneos (HABERMAS, 1986b, p. 377$){ }^{5}$

Habermas já enfrentara esses problemas na teoria do agir comunicativo, porém, de um modo que ele mesmo considera insatisfatório. Por isso, ele retoma esse trabalho na já citada réplica, onde elabora melhor as razões que o levam a pensar nas possibilidades de acoplagem entre mundo da vida e sistema. Ele argumenta que tal acoplagem não pode constituir problema em si mesma, visto que, em princípio, todos os fenômenos sociais podem ser descritos sob esses dois enfoques (HABERMAS, 1986b, p. 381). Porquanto, se é verdade que mecanismos integradores do sistema permeiam contextos da atividade comunicativa orientada por entendimento, também é verdade, segundo ele, que o mundo da vida não pode ser tido ingenuamente na conta de um conjunto de "esferas de comunicação isentas de poder", isto é, esferas situadas totalmente acima e a salvo do sistema e do agir estratégico (HABERMAS, 1986b, p. 383).

De outro lado, o processo de integração social não exige subordinação prévia a um determinado tipo de ação, seja ele de tipo comunicativo ou estratégico. Por isso, Habermas não considera problemático o fato de ele se servir do conceito de sistema, já que esse conceito

${ }^{5}$ J. A. Giannotti tambem parece compartilhar a tese sobre o ecletismo na obra de Habermas. 
se presta melhor do que outros para uma análise das condições atuais da sociedade e das patologias que Marx caracterizara como “abstrações reais” (HABERMAS, 1986b, p. 383).

Para enfrentá-las Habermas interpreta o mundo da vida e o sistema como "conceitos de ordem" que caracterizam aspectos distintos da configuração de uma sociedade em geral. Por isso, podem ser desacoplados em um nível geral de análise, já que a integração da sociedade em seu todo apresenta dois aspectos de um mesmo objeto que são distintos e, ao mesmo tempo, inseparáveis um do outro, os quais podem, no entanto, ser desacoplados sob um ponto de vista analítico. E nesse caso Habermas se considera justificado a aventar a hipótese de uma integração social em duas vias: a do mundo da vida e a do sistema.

A partir dessa distinção, ele consegue reformular seu conceito de sociedade: "A sociedade se compõe de contextos de ação de grupos integrados socialmente e estabilizados sistemicamente" (HABERMAS, 1986b, p. 379). Nessa linha de raciocínio ele passa a admitir duas classes distintas de mecanismos de integração social (ou duas ordens distintas de configuração da sociedade em geral), a saber: mecanismos de poder e de troca, de um lado; e mecanismos de entendimento, de outro, que abrem possibilidades de formação de entendimento e consenso mediante a linguagem comum. Entretanto, o modus operandi de cada um desses mecanismos é diferenciado: De um lado, os mecanismos de integração social possuem uma ligação intrínseca com o mundo da vida porquanto eles partem das orientações que os atores imprimem às suas ações, ou seja, eles possuem uma ligação íntima com estruturas do agir orientado por entendimento. Ao passo que os mecanismos integradores do sistema seguem uma lógica própria, impessoal, que passa ao largo da atividade comunicativa e do mundo da vida de participantes de uma sociedade. Eles permanecem exteriores às estruturas da ação. Por isso, as ordens produzidas por esse tipo de integração são geralmente contra-intuitivas, isto é, não são captadas pelo senso comum. (HABERMAS, 1986b, p. 380)

É interessante lembrar o modo como se dá a descoberta desses dois mecanismos configuradores da ordem da sociedade, os quais não estão disponíveis diretamente na consciência nem na vivência imediata dos participantes de uma interação. No entender de Habermas, eles só aparecem em dois momentos bem determinados: a) quando queremos avaliar sistematicamente o grau de evolução racional de uma sociedade e b) quando tentamos explicar crises ou patologias nela ocorrentes. Nesse momento nós "topamos", por assim dizer, com dois tipos fundamentais de crises. Crises de integração social, quando o que está em jogo se liga à autocompreensão dos próprios envolvidos. Ou crises sistêmicas de autorregulação da sociedade acessíveis a uma observação científica empírica. 


\subsection{Problemas decorrentes da diferenciação e da desacoplagem entre mundo da vida e sistema}

Ante o pano de fundo acima esboçado, Habermas, apoiando-se na teoria de sistemas de N. Luhmann, formula a tese sobre a possibilidade de desacoplagem entre dois níveis distintos da sociedade. De um lado, ela pode ser entendida como sistema; e de outro, como mundo da vida. Segundo essa tese, a dinâmica da delimitação de um sistema (que constitui uma perspectiva a partir de dentro) em relação a um determinado entorno, mais complexo, (que constitui uma perspectiva a partir de fora) imigra para dentro da própria sociedade. (HABERMAS, 1986b, p. 384) E a partir daí desaparece a possibilidade de uma relação harmônica entre partes e um todo, remanescendo apenas processos de diferenciação. No decorrer desses processos sistemas parciais passam a se delimitar uns em relação aos outros, definindo-se reciprocamente como entorno.

Habermas lembra que existem várias maneiras de utilizar o modelo de sistema. No capítulo VII do segundo volume da Teoria do agir comunicativo (HABERMAS, 1981, v. 2), ele afirma que Parsons e seus discípulos o empregam de modo puramente analítico, desenvolvendo a imagem de sociedades capitalistas avançadas imunes a patologias sociais. Isso acontece, segundo ele, porque eles anulam a distinção entre sistema e mundo da vida o que os impede de vislumbrar os indicadores de patologias de uma modernidade que, segundo Weber, está se decompondo gradualmente (HABERMAS, 1981, v. 2, p. 443-444).

Convém frisar, no entanto, que Habermas não se limita a utilizar a lógica funcionalista da teoria de sistemas para fins próprios. Ele vai além, configurando um princípio teórico crítico que é sensível não somente à separação analítica entre integração por via da ação social e por via do sistema, mas também á dinâmica evolutiva inerente à própria sociedade que faz com que o objeto da teoria da sociedade se modifique devido à dinâmica da evolução social, ou seja: quanto mais a reprodução material do mundo da vida, estruturado comunicativamente, se amplia e se diferencia, tanto mais ele se complexifica. Por isso, ela necessita de uma análise em termos de teoria de sistemas, a qual é capaz de desvendar os aspectos contra-intuitivos da socialização. Entretanto, convem lembrar que Habermas continua atribuindo, mesmo assim, a primazia ao mundo da vida. E essa decisão faz com que ele se defronte com os fenômenos de uma racionalização contraditória, já estigmatizada por Max Weber como reificação ou perda da liberdade e do sentido (HABERMAS, 1981, v. 2, p. 447), a qual é provocada pela intromissão ou imigração de elementos do sistema para o mundo da vida de que resulta uma "colonização" do último (HABERMAS, 1985). 
Em "O discurso filosófico da modernidade" ele argumenta que já no século XVIII o desengate entre mundo da vida e sistema e a subseqüente emigração do sistema para o mundo da vida foi interpretado como separação, rompimento, desunião, ruptura e "reificação" de formas tradicionais de vida. E lembra que Hegel chega a falar em "totalidade fraturada do elemento ético" (HABERMAS, 1986a).

\subsection{Críticas à Tese Habermasiana da desacoplagem entre mundo da vida social e sistema}

Dentre as principais críticas dirigidas à tese da desacoplagem convém salientar as que são levantadas por teóricos de esquerda, os quais se opõem à "utilização crítica da própria análise sistêmica como um todo". Elas não se dirigem, a bem da verdade, contra a tese da desacoplagem enquanto tal, mas ao uso que Habermas faz dela para descrever as patologias das sociedades modernas. Segundo esses críticos, a utilização da teoria de sistemas por parte de Habermas equivale a uma renúncia aos ideais da tradição socialista e da Escola de Frankfurt, bem como da democracia radical, tão cara a Habermas.

Contra essa objeção Habermas formula, em um primeiro momento, uma resposta direta de cunho existencial: "Se isso fosse verdade", isto é, se a assunção da teoria de sistemas na teoria do agir comunicativo tivesse como conseqüência necessária o abandono das idéias democrático-radicais, "eu não teria tido a energia suficiente para escrever um livro tão abrangente sobre a teoria do agir comunicativo" (HABERMAS, 1986b, p. 377).

Em um segundo momento ele apresenta um argumento apoiado na natureza da sua teoria da sociedade como um todo, o qual pode ser resumido da seguinte forma: esta teoria lança fora, certamente, as certezas criadas por uma filosofia da história orientada pelo paradigma da filosofia da consciência, que é monológico. Porém, ela não é obrigada a abandonar, por este simples fato, a sua pretensão crítica. Ela apenas procura outro caminho para fundamentá-la, já que, segundo ele, a manutenção da pretensão crítica original não implica necessariamente a manutenção do paradigma da consciência do sujeito, que orientou os trabalhos da Teoria Crítica da Escola de Frankfurt, a qual serviu, mesmo assim, de modelo e inspiração inicial para J. Habermas. Tampouco implica uma dependência exclusiva da hermenêutica ou da fenomenologia.

Há uma passagem na citada réplica de Habermas que traduz, a meu ver, de forma plástica a sua convicção, segundo a qual o novo paradigma cooperativo e interdisciplinar por ele introduzido consegue substituir, sem nenhum tipo de prejuízo nem reduções subreptícias, o paradigma da autoconsciência. E sem qualquer tipo de dano para sua pretensão crítica: 
A crítica exercida de modo formal e pragmático ilumina o cenário atual no qual as próprias teorias sociológicas que estudam a ação têm de operar: o barco avariado da filosofia da praxis não conseguiria mover-se novamente se ficasse na dependência exclusiva de péças de reposição adquiridas nas docas do interacionismo simbólico ou da fenomenologia social (HABERMAS, 1986b, p. 377).

Habermas pensa que as tarefas atuais de uma teoria crítica da sociedade se concentram mais no esclarecimento da esfera pública sobre problemas de inclusão do outro e sobre ambivalências profundas que marcam sociedade mundial. Por isso, é necessário buscar novas possibilidades de acoplagem, novas mediações e traduções inteligentes, a fim de chegar a um entendimento intersubjetivo, cooperativo e interdisciplinar sobre novas formas de superar velhas patologias e de construir novas possibilidades para enfrentar inusitados desafios que espreitam, a cada passo, a humanidade (HABERMAS, 1986b, p. 392).

É interessante observar que a tese sobre as possibilidades de desengate e de acoplagem e entre mundo da vida e sistema abre um espaço para Habermas configurar uma espécie de terceira via situada entre duas tendências teóricas opostas:

a) A de certos autores, especialmente marxistas, que continuam insistindo na necessidade de ancorar os meios de controle da sociedade no mundo da vida de certas classes. Nessa linha de raciocínio seria necessário concentrar, acima de tudo, esforços para solidificar um quadro institucional a fim de submeter a manutenção do sistema da sociedade às restrições normativas de um mundo da vida social.

b) De outro lado, há os que seguem em uma direção contrária. Porém, no final das contas, eles recobrem o mundo da vida com formas de uma racionalidade funcionalista, econômica e administrativa, incompatíveis com ele. Porquanto esse procedimento gera, por um lado, uma consolidação das estruturas de classes existentes e uma subordinação do mundo da vida a pressões da reprodução material. Habermas caracteriza esse processo como "mediatização do mundo da vida" ou ainda como "colonização do mundo da vida". Em linguagem marxiana, tal processo tal processo equivaleria a uma "subsunção total do mundo da vida sob os imperativos de um processo de produção capitalista completamente desligado do trabalho concreto e da orientação por valores de uso" (HABERMAS, 1986b, p. 392).

Habermas tenta enveredar por uma terceira via argumentando que os meios sistêmicos de controle da sociedade, especialmente o dinheiro e o poder, possuem per se um valor evolucionário próprio que não depende apenas nem exclusivamente da institucionalização dos seus efeitos em classes específicas, ao contrário do que pensava Marx. Por isso acrescenta um 
terceiro meio de integração social capaz de fornecer sentido às acoplagens mediadoras entre mundo da vida e sistema: a solidariedade.

\section{CONCLUSÃO}

Parece-me apropriado encerrar esses apontamentos sobre um modelo teórico visando a cooperação entre a filosofia e as ciências, consignando a seguinte conjectura: A teoria do agir comunicativo, que em 1981 ainda se apresentava como um projeto aberto, uma" quasepromessa", talvez não tenha mudado muito de lá para cá no que tange à compreensão de sua tarefa precípua que consiste em analisar o mundo social sem perder de vista patologias e ambivalências profundas a ele inerentes. E tal projeto aberto depende de buscas reiteradas de possibilidades de acoplagem entre o mundo da vida e o sistema, da elaboração de mediações e de traduções que, através da crítica racional de pretensões de validade, possibilitam entendimento intersubjetivo e interdisciplinar sobre o homem, sua filosofia, suas ciências e sua sociedade.

E a mola que impulsiona esse trabalho imenso deve ser procurada num conceito falibilista, porém, não derrotista, de razão comunicativa e numa peculiar ideia muito peculiar de humanidade e de comunicação que já aparece formulada em 1970:

Humanidade é a audácia que nos resta no final de tudo, após termos entendido que o único meio que temos para opor às ameaças decorrentes de uma fragilidade universal é a comunicação, um meio frágil e repleto de riscos (HABERMAS, 1971). 


\section{REFERENCIAS}

HABERMAS, J. Philosophisch-politische Profile. Frankfurt: M: Suhrkamp, 1971.

.Die neue unübersichtlichkeit: Kleine politische Schriften V. Frankfurt: M.: Suhrkamp, 1985.

Der philosophische Diskurs der Moderne: Zwölf Vorlesungen. 3. ed., Frankfurt: M.: Suhrkamp, 1986a.

Entgegnung. In: HONNETH, A.; JOAS, H. (Ed.) Kommunikatives Handeln: Beiträge zu Jürgen Habermas "Theorie des Kommunikativen Handelns". Frankfurt: M.: Suhrkamp, $1986 b$. 1999.

Wahrheit und Rechtfertigung? philosophische Aufsätze. Frankfurt: M.: Suhrkamp, . 3. 3. ed. ampl. Frankfurt: M: Suhrkamp, 1984.

. Theorie des kommunikativen Handelns. Frankfurt: M: Suhrkamp, 1981. v. 1 - 2 3. ed. rev. Frankfurt: M: Suhrkamp, 1985. v. $1-2$.

Zwischen Naturalismus und Religion: philosophische Aufsätze. Frankfurt: M.: Suhrkamp, 2005.

KANT, I. Kritik der reinen vernunft: Werkausgabe. Frankfurt: M.: Suhrkamp, 1974. v. XVI, XVII.

PUNTEL, L. B. Estrutura e ser: um quadro referencial teórico para uma filosofia sistemática. São Leopoldo: Unisinos, 2008. 